\title{
Effects of Instructor Background and Delivery Modality on Students' Perceptions of a Social Media Lecture
}

\author{
Marilyn Eastman and William J. Jones
}

\begin{abstract}
Increasingly, marketing departments are recognizing the importance of teaching students the appropriate skills to adapt to the quickly evolving business environments (Granitz and Koernig 2011; Rinaldo et al. 2013; Tuten and Marks 2012; Wymbs 2011). This is especially relevant in marketing education where organizations expect marketing graduates to be equipped with skills in current information technologies used to manage communication with stakeholders and make complex data-driven marketing decisions (Granitz and Koernig 2011). Recent research indicates that at least some employers are currently dissatisfied with the technology skillsets of marketing graduates (Harrigan and Hulbert 2011; Kaplan et al. 2009). The purpose of this research is to determine whether there are significant differences in student attitudes toward faculty credibility, perceptions of learning, and attitudes toward digital marketing. We explore these questions within an experimental setting that manipulates whether the content of a digital marketing module was created by an industry expert versus academic and whether the delivery modality is face-to-face versus recorded. The results of this study reveal that whether or not an instructor presents themselves as from industry or academia and the modality of lecture delivery are important, though not interactive, factors in determining students' perceptions toward a social media marketing lecture. Specifically, we find that in-person lecturing positively influences students' perceptions of the lecturer across likeability, competence, character, and delivery variables. Face-toface instruction was also positively associated with positive characteristics derived from a specific lecture such as how enjoyable it was and whether it should be taught to future classes.
\end{abstract}

\section{References available upon request.}

M. Eastman $\bullet$ W.J. Jones $(\bowtie)$

University of South Dakota, Vermillion, SD, USA

e-mail: Marilyn.Eastman@coyotes.usd.edu; William.Jones@usd.edu 